\title{
Developing successful theories in marketing and R-A theory: Historical evolution? Other drivers? What's important? What's next?
}

\author{
Shelby D. Hunt
}

Received: 25 August 2011 / Accepted: 28 August 2011 /Published online: 6 October 2011

(C) Academy of Marketing Science 2011

"Developing Successful Theories in Marketing" (hereafter, DSTM, this issue) used resource-advantage (R-A) theory as a case-example for investigating why some theories in marketing are more successful than others. After acknowledging the pitfalls in generalizing from a single case, the article developed five guides for authors seeking to develop successful theories: (1) focus theory development on important issues in macromarketing and/or micromarketing, (2) craft theories with high explanatory and predictive power, (3) respect other disciplines' literatures, (4) publish the theory in nonmarketing journals, and (5) explore the normative implications of the theory.

I thank Professors S. Adam Brasel (hereafter, SAB), Colin Campbell (hereafter, CC), and Bodo B. Schlegelmilch (hereafter, BBS) for their thoughtful commentaries. It is gratifying that all three find merit in the article's use of R-A theory to develop suggested guides. Indeed, given the critical stance of most commentaries, any author would be pleased to find that commentators identify his or her work as filling an "aching void" (CC), or that it provides a "valuable insight" (SAB), or that it is "most intriguing" (CC), or that it "could not have come at a better time" (BBS). Nonetheless, the three commentators raise several important issues, which can be grouped into four categories: (1) How did R-A theory evolve? (2) Are there other success drivers? (3) Who and what determines the importance of a research topic? (4) What is the next step for interested readers?

\section{S. D. Hunt $(\bowtie)$}

Department of Marketing, Rawls College of Business,

Texas Tech University,

Lubbock, TX 79409-2101, USA

e-mail: shelby.hunt@ttu.edu

\section{R-A theory's evolution}

SAB inquires: "How did the theory arrive in its final form?" What "road did it take to reach its elegant end-form summary?" "Which articles provided a key. . . [to its] developmental process?" Similarly, CC inquires what key "diagnostics" were available? In response, even though I note that R-A theory is a work in progress (which implies that the current version of the theory is not considered its "final form"), understanding the historical development of any theory is important, including the historical development of R-A theory in its current form.

Marketing historians distinguish between research that focuses on the history of marketing practice (e.g., histories of advertising and retailing) and the history of marketing thought (e.g., histories of concepts, theories, and schools of thought). In the philosophy of science, issues that concern the historical evolution of a theory are customarily discussed using the "discovery versus justification" distinction. That is, how scientists go about creating or developing hypotheses, laws, and theories is considered to be in the context of discovery. In contrast, how scientists go about explaining phenomena, predicting phenomena, testing theories, and validating hypotheses, laws, and theories is considered to be in the context of justification. If there existed a set of systematic rules and procedures that were optimal for the discovery of hypotheses, laws, and theories, this set of rules and procedures would constitute a logic of discovery.

Hunt (2010), in Figure 1.1, shows five paths, routes, or procedures that are often proposed (or reported to be likely) to lead to the development of theories: eureka, dreams, metaphor recognition, inducing generalizations from data, and deducing generalizations from foundational premises. After arguing that there exists no logic of discovery, Hunt 
(2010, p. 25) concludes that "many, if not most, major scientific discoveries are flashes of perceptual insight and are not the result of following some rigorously prescribed procedure." So it has been with R-A theory.

I have developed a working paper on the historical evolution of R-A theory that is currently titled "The Evolution of Resource-Advantage Theory: Six Events, Six Realizations, Six Contributions." The article, a personal retrospective on the development of R-A theory, identifies six of the key events/experiences that influenced the development of the structure and foundational premises of R-A theory. I call these events/experiences "realizations" because each of them resulted in Robert M. Morgan and/or me realizing the existence or importance of some issue, concept, approach, theory, or state of affairs. These realizations contributed to the development of specific aspects of R-A.

Although this short reply cannot provide a detailed history of the development of R-A theory, I can report the six events chronicled in the working paper. Stated succinctly, the six are: (1) B. J. "Bud" LaLonde emphasizes the works of Alderson (1957, 1965), (2) Rob Morgan suggests an article on the resource-based theory of the firm, (3) Roy Howell suggests a presentation on R-A theory, (4) Randy Sparks shows me a "socialist calculation" article, (5) Kim Boal suggests the Journal of Management Inquiry as a publication outlet, and (6) Bob Phillips discusses his work on "firm effects vs. industry effects." I will be pleased to share a draft of this article on R-A theory's historical development with readers who are interested.

\section{Other success drivers}

SAB suggests that there likely "are other routes a theory can take," that there are "other drivers of success," and perhaps a "series of reflective articles can begin to offer a master list of success drivers." Similarly, as to success drivers, BBS maintains that, because "we know that Hunt actually has a lot to say about scientific realism," he is disappointed that the article was "silent" about the "fundamental distinction between positivists and relativists of various shades." Furthermore, BBS argues, "the article evades the prominence some postmodernist scholars have gained in our discipline."

In response, as to whether the article "evades" postmodernism, readers are asked to recall that the purpose of DSTM was to use R-A theory as a case-example to explore why some theories in marketing are more successful than others (given caveats about generalizing from a single case). Of course, some postmodernist articles have been successful, but postmodernism had nothing to do with the success of R-A theory. Therefore, the article did not "evade" postmodernism; it simply was not relevant to the article's purpose.

As to the absence of a discussion concerning scientific realism and how it differs from the views of "positivists and relativists of various shades," it is true that R-A theory "adopts the epistemology of scientific realism. . . [and] if a foundational premise is found to be false, then it should be replaced with a premise that better describes the real world competition in market-based economies" (Hunt and Morgan 1995, p. 5). Also, it is true that R-A theory's adoption of scientific realism implies the adoption of its four fundamental tenets: classical realism, fallibilistic realism, critical realism, and inductive realism. Therefore, it could be the case that part of R-A theory's success results from marketers' knowing that the theory adopts realism, rather than positivism or relativism. At the time of writing the article, it did not seem to me that the adoption of realism was a success factor for R-A theory. BBS apparently thinks that it was. I hope he is correct.

As to "other routes a theory can take," I agree that there are other success drivers. The five identified in DSTM are just a start. I also agree with SAB's suggestion that a "series of reflective articles" on success drivers would be a useful project. Therefore, I suggest that authors develop (and editors consider favorably) research that focuses on other success factors.

\section{A focus on important issues}

CC maintains that what "seems crucial for developing successful theory is a keen eye for recognizing not only gaps in the literature, but issues of real relevance to marketing," but "knowing which issues to devote effort to is incredibly difficult." Also, BBS notes that what issues are important "is open to interpretation" and raises the question: "important for whom?" He discusses the importance issue as being a part of the debate on the "trade-off between rigor versus relevance."

In response, I believe that the issues raised in DSTM are not well-categorized by the alleged trade-off between rigor versus relevance. Too often, it seems to me, the "rigor" in the debates concerning the alleged trade-off is equated with "sophisticated mathematics and statistics." I make two points here. First, research that uses sophisticated mathematics and/or statistics can be highly relevant. Therefore, I do not believe there is always a trade-off. Second, highly rigorous research need not use sophisticated mathematics and/or statistics. Indeed, R-A theory, whose structure and foundations do not employ sophisticated mathematics and/ or statistics, is rigorous because of the meticulous manner in which the foundational premises and structure are developed. Therefore, for these two reasons, the "rigor 
versus relevance" way of framing the issues, I believe, is seriously flawed.

The point that I am making in DSTM is not that reviewers and editors are making an inappropriate trade-off that favors articles with sophisticated mathematics and statistics over those that focus on relevant topics. Rather, the point I am making is that reviewers and editors are valuing only two kinds of articles, (1) those that report the results of experimental studies on small, consumer behavior issues and (2) those that involve the tweaking of some mathematical model related to some minor marketing issue. Therefore, the value system of marketing reviewers and editors is a significant impediment to the development of successful marketing theories and the intellectual health of the marketing discipline.

The preceding notwithstanding, the issue of "important for whom?" remains. I once answered the "for whom" question this way:

The prime directive for scholarly research in marketing is the same as for all sciences: to seek knowledge. The knowledge must be intersubjectively certifiable and capable of describing, explaining, and predicting phenomena. Sometimes the knowledge will assist marketing managers in making decisions. Other times the knowledge will guide legislators in drafting laws to regulate marketing activities. At still other times the knowledge may assist the general public in understanding the functions that marketing activities provide society. Finally, at the risk of "waxing philosophical," the knowledge may simply assist marketers in knowing, a not inconsequential objective.

(Hunt 1978, p. 108)

It seems to me that the view that marketing knowledge has several stakeholders, each of which is important, still has merit.

With respect to the stakeholders of R-A theory, one might suspect that the theory is primarily of interest to academics, not managers. However, my experience does not bear this out. Indeed, I have presented R-A theory to many groups of practitioners and their responses have been uniformly positive. To them, the theory "rings true." Most often, managers quickly find ways that R-A theory (e.g., the nine-celled, competitive position matrix) can be applied in their firms. Other academics have reported similar experiences when they present the theory to managers.

Finally, with respect to theories that address important issues, it is true that importance "is open to interpretation," as BBS puts it. I do have a suggestion, however. If you, as an author, believe that the topic you are researching is very important, do not leave it to chance that the reviewers of your manuscript will agree with you. Early in your article you should present arguments that your article addresses an important topic. As an example of how to do this, the very first paragraph of "Organizational Commitment and Marketing" (Hunt et al. 1985) might serve as a useful model to keep in mind. (Note that the discussion in the first paragraph of that article takes place in the first paragraph.)

\section{What's next?}

SAB inquires: "Which subsequent pieces by the author on the same topic are the key next steps for a reader looking to explore the theory further?" R-A theory is less than two decades old - it is very much a work in progress. If a researcher is interested in exploring the arguments concerning the foundational premises of the theory, the place to start would be Chapter 5 of Hunt (2000) and Chapter 13 of Hunt (2010). For investigating the public policy implications of the theory, I suggest readers start with Hunt and Arnett (2001) and Grengs (2006). For exploring how the theory can provide a foundation for various types of strategy, begin with Hunt and Derozier (2004) and Chapter 15 of Hunt (2010). For those interested in how R-A competition promotes increases in productivity and economic growth, start with Chapters 7-9 of Hunt (2000). For investigating how the theory does (and does not) relate to other theories and research traditions, see Chapters 2-4 of Hunt (2000). For how to use the theory as a foundation for empirical research, see Wittman et al. (2009). For investigating the relationship between R-A theory and the service-dominant logic, see Hunt (2004) and Hunt and Madhavaram (2006a). For suggestions on how to use R-A theory in the classroom, see Hunt and Madhavaram (2006b). There is still much work to do.

In conclusion, I again thank Professors S. Adam Brasel, Colin Campbell, and Bodo B. Schlegelmilch for their thoughtful commentaries. I have learned a great deal from the numerous critiques of R-A theory. Unquestionably, the theory has benefited from its being closely scrutinized - as it should.

\section{References}

Alderson, W. (1957). Marketing behavior and executive action. Homewood: Richard D. Irwin.

Alderson, W. (1965). Dynamic marketing behavior. Homewood: Richard D. Irwin, Inc.

Grengs, C. M. (2006). Verizon v. Trinko: from post-Chicago antitrust to resource-advantage competition. Journal of Law, Economics, \& Policy, 2(1), 105-144.

Hunt, S. D. (1978). A general paradigm of marketing: in support of the three dichotomies model. Journal of Marketing, 42(2), 107-110.

Hunt, S. D. (2000). A general theory of competition: Resources, competences, productivity, economic growth. Thousand Oaks: Sage. 
Hunt, S. D. (2004). On the services-centered dominant logic for marketing. Journal of Marketing, 68(1), 21-22.

Hunt, S. D. (2010). Marketing theory: Foundations, controversy, strategy, resource-advantage theory. Armonk: M.E. Sharpe.

Hunt, S. D., \& Arnett, D. B. (2001). Competition as an evolutionary process and antitrust policy. Journal of Public Policy and Marketing, 20(1), 15-25.

Hunt, S. D., \& Derozier, C. (2004). The normative imperatives of business and marketing strategy: grounding strategy in resourceadvantage theory. The Journal of Business and Industrial Marketing, 19(1), 5-22.

Hunt, S. D., \& Madhavaram, S. (2006a). The service-dominant logic of marketing: Theoretical foundations, pedagogy, and resourceadvantage theory. In R. F. Lusch \& S. L. Vargo (Eds.), The service-dominant logic of marketing: Dialog, debate, and directions (pp. 85-90). Armonk: M.E. Sharpe.

Hunt, S. D., \& Madhavaram, S. (2006b). Teaching marketing strategy: using resource-advantage theory as an integrative theoretical foundation. Journal of Marketing Education, 28(2), 93-105.

Hunt, S. D., \& Morgan, R. M. (1995). The comparative advantage theory of competition. Journal of Marketing, 59(2), 1-15.

Hunt, S. D., Chonko, L. B., \& Wood, V. R. (1985). Organizational commitment and marketing. Journal of Marketing, 49(Winter), 112-126.

Wittman, C. M., Hunt, S. D., \& Arnett, D. B. (2009). Explaining alliance success: competences, resources, relational factors, and resource-advantage theory. Industrial Marketing Management, $38,743-756$. 